\title{
Factors Affecting Cardiovascular Risk in Children, Adolescents, and Young Adults with Type 1 Diabetes
}

\author{
Ingrida Stankute $\mathbb{D}^{\mathrm{D}}{ }^{1}$ Rimante Dobrovolskiene, ${ }^{1}$ Evalda Danyte, ${ }^{1}$ \\ Dovile Razanskaite-Virbickiene, ${ }^{1}$ Edita Jasinskiene, ${ }^{1}$ Giedre Mockeviciene, ${ }^{1}$ \\ Dalia Marciulionyte, ${ }^{2}$ Valerie M. Schwitzgebel, ${ }^{3,4}$ and Rasa Verkauskiene ${ }^{1,2}$ \\ ${ }^{1}$ Medical Academy, Lithuanian University of Health Sciences, Kaunas, Lithuania \\ ${ }^{2}$ Institute of Endocrinology, Lithuanian University of Health Sciences, Kaunas, Lithuania \\ ${ }^{3}$ Pediatric Endocrine and Diabetes Unit, Department of Pediatrics, Gynecology and Obstetrics, University Hospitals of Geneva, \\ 1211 Geneva, Switzerland \\ ${ }^{4}$ Diabetes Center of the Faculty of Medicine, University of Geneva, 1211 Geneva, Switzerland
}

Correspondence should be addressed to Ingrida Stankute; ingridutes@gmail.com

Received 10 November 2018; Accepted 25 March 2019; Published 16 May 2019

Academic Editor: Konstantinos Papatheodorou

Copyright (c) 2019 Ingrida Stankute et al. This is an open access article distributed under the Creative Commons Attribution License, which permits unrestricted use, distribution, and reproduction in any medium, provided the original work is properly cited.

\begin{abstract}
Cardiovascular risk and obesity are becoming major health issues among individuals with type 1 diabetes (T1D). The aim of this study was to evaluate cardiovascular risk factors and obesity in youth with T1D in Lithuania. Methods. 883 patients under 25 years of age with T1D for at least 6 months were investigated. Anthropometric parameters, blood pressure, and microvascular complications were evaluated, and the lipid profile and HbAlc were determined for all patients. Results. Study subjects' mean $\mathrm{HbAlc}$ was $8.5 \pm 2 \%$; $19.5 \%$ were overweight and $3.6 \%$ obese. Hypertension and dyslipidemia were diagnosed in $29.8 \%$ and $62.6 \%$ of participants, respectively. HbAlc concentration was directly related to levels of total cholesterol $(r=0.274, p<0.001)$, LDL $(r=0.271, p<0.001)$, and triglycerides $(r=0.407, p<0.001)$ and inversely associated with levels of $\mathrm{HDL}(r=0.117, p=0.001)$. Prevalence of dyslipidemia increased with duration of diabetes $(p<0.05)$. Hypertension was more prevalent in overweight and obese compared to normal-weight patients ( 40.6 and $65.6 \mathrm{vs.} 25.6 \%$, respectively, $p<0.001)$. Frequency of microvascular complications was higher among patients with dyslipidemia $(27.2 \mathrm{vs.} 18.8 \%, p=0.005)$ and among those with hypertension $(25.9$ vs. $23.2 \%, p<0.001)$. Conclusion. The frequency of cardiovascular risk factors is high in youth with T1D and associated with diabetes duration, obesity, and metabolic control.
\end{abstract}

\section{Introduction}

The main cause of death in European countries is cardiovascular diseases (CVD) [1]. Several studies showed that atherosclerosis presents more frequently in people with diabetes. This is usually explained by persistently elevated glucose levels in the blood $[2,3]$.

CVD tend to present at a younger age in patients with diabetes than in the general population [4]. The SEARCH for Diabetes in Youth Study showed that significant complications severely affect the quality of life of diabetics early in their life [5]. Therefore, adolescence and young adulthood are the best times for actions to lower cardiovascular risk [6].

The other growing issue in type 1 diabetes (T1D) patients is obesity, which aggravates the risk of hypertension and dyslipidemia [7].

The aim of our study was to analyze the risk factors for CVD in children and young adults under the age of 25 years with T1D in Lithuania. 


\section{Materials and Methods}

2.1. Subjects. The presented cohort included 883 subjects from the recent joint Lithuanian-Swiss project "Genetic Diabetes in Lithuania," which had 1209 subjects overall, covering all children and $70 \%$ of young adult (under the age 25) patients with T1D in Lithuania, described previously [8].

This analysis included patients with established diabetes longer than 6 months and treated with insulin: 590 of them $(66.8 \%)$ were from 1- to 17 -year-old children and adolescents, and 293 are young adults (33.2\%) from 18 to 25 years old. Subjects with diabetes duration less than 6 months were not included in this analysis due to the weight fluctuation and metabolic instability that are usually seen at the onset and initial therapy of diabetes [9]. None of the study participants were taking any medication affecting body composition, blood pressure, or renal function.

At the time of involvement in the project, data about age, duration of T1D, insulin delivery method (pump/injection), and total daily insulin dose $(\mathrm{U} / \mathrm{kg} / \mathrm{d})$ were collected and clinical and laboratory assessments done. The participants were consulted by a single ophthalmologist for evaluation of diabetic retinopathy and a pediatric or adult neurologist for assessment of diabetic neuropathy.

The Lithuanian Bioethics Committee granted the approval for this biomedical research (No. BE-2-5). Subject information forms and informed consent forms were signed by each participant or official representative.

2.2. Clinical Assessment and Examination. Anthropometric parameters were measured by clinical nurses at the Endocrinology Department of the Hospital of Lithuanian University of Health Sciences. At this department, the Harpenden Stadiometer (Holtain, Crymych, UK) is used for height measurement. Patients' height was measured to the nearest $\pm 0.1 \mathrm{~cm}$ three times, then the average was estimated for analyses. seca 700 medical scales (seca GmbH \& Co. KG) were used for weight in $\mathrm{kg}$, with precision of $0.1 \mathrm{~kg}$.

For body mass index (BMI), the equation weight in $\mathrm{kg} /$ recumbent length or standing height in $\mathrm{m}^{2}$ was used.

For participants under 19 years, a BMI $z$-score was evaluated according to age and gender using the references of the World Health Organization (WHO); for participants aged 19 to 25 years, a BMI $z$-score was evaluated according to the references of WHO for 19-year-old individuals, assuming that their linear growth is over.

For all participants, normal weight was defined as BMI ranging from -2 standard deviations (SD) to less or equal to $+1 \mathrm{SD}$ (which corresponds to BMI $25 \mathrm{~kg} / \mathrm{m}^{2}$ at 19 years); overweight was defined as BMI less than $+2 \mathrm{SD}$ (which corresponds to BMI $30 \mathrm{~kg} / \mathrm{m}^{2}$ at 19 years), obese as BMI $>+2 \mathrm{SD}$, and underweight as $\mathrm{BMI}<-2 \mathrm{SD}$.

A medical measuring tape was used for waist and hip measurements. The approximate middle point between the lower margin of the last palpable rib and the top of the iliac crest was measured, to the nearest $\pm 0.1 \mathrm{~cm}$, for waist circumference [10]. Hip circumference was measured at the widest point of the buttocks, to the nearest $\pm 0.1 \mathrm{~cm}$.
In analyses, the waist-hip ratio (waist circumference $(\mathrm{cm}) /$ hip circumference $(\mathrm{cm})$ ) and waist-to-height ratio (WtHR) (waist circumference $(\mathrm{cm}) /$ height $(\mathrm{cm})$ ) were used. The waist-hip ratio $\geq 0.90 \mathrm{~cm}$ for men and $\geq 0.85 \mathrm{~cm}$ for women were considered significantly increased [10]. WtHR $<0.5 \mathrm{~cm}$ was considered as optimal [11].

Arterial blood pressure for children and adults was measured after sitting in silence for $5 \mathrm{~min}$ using an oscillometric sphygmomanometer in the left arm with appropriate cuff size. For children, "The Fourth Report from the National High Blood Pressure Education Program (NHBPEP) Working Group on Children and Adolescents" guidelines was used to classify measurements of arterial blood pressure: "Normal $\mathrm{BP}$ was defined as systolic blood pressure (SBP) and diastolic blood pressure (DBP) less than the 90th percentile for sex, age, and height. Hypertension was defined as average SBP or DBP that was greater than or equal to the 95th percentile for sex, age, and height on at least three separate occasions" [12].

Measurements of arterial blood pressure in adults were classified according to the American Heart Association (AHA) guidelines: "Normal blood pressure defined as SBP $<120 \mathrm{mmHg}$ and $\mathrm{DBP}<80 \mathrm{mmHg}$, hypertension beginning at $140 / 90 \mathrm{mmHg}$ and higher" [13].

2.3. Laboratory Analyses. Glycosylated hemoglobin (HbA1c) and lipid profiles were measured by the UniCel DxC 800 Synchron system (Beckman Coulter, USA). The normal cutoff values of $\mathrm{HbAlc}$ were $4-6 \%(20 \mathrm{mmol} / \mathrm{mol}-42 \mathrm{mmol} / \mathrm{mol})$. International Society for Pediatric and Adolescent Diabetes (ISPAD) guidelines were used to define optimal metabolic control when $\mathrm{HbAlc}<7.5 \%(58 \mathrm{mmol} / \mathrm{mol})$ for children and adolescents and $<7 \%$ for young adults with reference to American Diabetes Association guidelines [14, 15].

Normal values for low-density lipoprotein cholesterol (LDL), high-density lipoprotein cholesterol (HDL), and triglycerides (Tg) were defined as $<2.6 \mathrm{mmol} / \mathrm{l},>1.1 \mathrm{mmol} / \mathrm{l}$, and $<1.7 \mathrm{mmol} / \mathrm{l}$, respectively $[14,16]$. Normal values for total cholesterol were defined as $<5.2 \mathrm{mmol} / \mathrm{l}$ for patients $\geq 16 \mathrm{yrs}$ and $<5.5 \mathrm{mmol} / \mathrm{l}$ for children under $16 \mathrm{yrs}$. If at least one lipid value was abnormal, dyslipidemia was considered to be present.

2.4. Evaluation of Microvascular Diabetes Complications. All participants were screened for microvascular diabetes complications at the same Endocrinology Department. A single diabetes ophthalmologist and an adult/pediatric neurologist consulted with all diabetes patients for the presence of retinopathy and neuropathy, respectively. Diabetic retinopathy was identified from stereoscopic fundal examination. Sensations for vibration, pressure, and temperature were evaluated for each patient, and all of them were surveyed with the Michigan Neuropathy Screening Questionnaire. If $\geq 2$ of these tests were abnormal, peripheral neuropathy was diagnosed $[8,17,18]$.

For diabetic kidney damage, a 24-hour urine albumin excretion rate (AER) was evaluated. AER $<30 \mathrm{mg} / 24 \mathrm{~h}$ was defined as normal, $30-300 \mathrm{mg} / 24 \mathrm{~h}-$ microalbuminuria, and $>300 \mathrm{mg} / 24 \mathrm{~h}$-macroalbuminuria [19]. 
2.5. Statistical Analyses. The IBM SPSS Statistics Base version 22.0 was used for statistical analysis of the data. In case of normal data distribution, Student's 2-tailed $t$ test, $\chi^{2}$ statistics, and parametric one-way ANOVA were used. For nonnormally distributed data, the Mann-Whitney $U$ test was used, and for ordinal data, Kruskal-Wallis one-way ANOVA was used. For estimation of trends, linear regression models were used. For testing the hypothesis about relationships between dichotomous-dependent variables and continuous predictors, binary logistic regression analysis was carried out. $p$ values $<0.05$ were considered as statistically significant. All $p$ values were two-sided.

\section{Results}

3.1. General Characteristics and Weight Status. Of the 883 subjects enrolled for the current analysis, $49.2 \%(n=434)$ were males. The mean age of study subjects was $16.2 \pm$ $5.6 \mathrm{yrs}$. The average diabetes duration was $6.7 \pm 4.8 \mathrm{yrs}$ (0.5-24.73, median 5.6yrs). The distribution of patients by duration of T1D was as follows: $0.5-4$ years $45.4 \%$ $(n=401), 5-9$ years $30.9 \%(n=273), 10-14$ years $17.9 \%$ $(n=158), 15-19$ years $4.3 \%(n=38)$, and $\geq 20$ years $1.5 \%$ $(n=13)$.

The mean BMI $z$-score in the whole cohort was $0.29 \pm$ 0.99 . $75.8 \%$ of study subjects $(n=666)$ were of normal weight, $19.5 \%(n=171)$ overweight, $3.6 \%(n=32)$ obese, and $1.1 \%(n=10)$ underweight. The distribution of weight status among different age groups is shown in Figure 1 $(p>0.05) .20 .5 \%$ of females and $18.3 \%$ of males were overweight $(p>0.05)$, and $3.3 \%$ of females and $3.9 \%$ of males were obese $(p>0.05)$.

Clinical characteristics according to weight group are shown in Table 1. Hypertension was more frequent among overweight and obese patients than among normal weight patients ( $40.6 \%$ and $65.6 \%$ vs. $25.6 \%$, respectively, $p<0.05)$.

$21.8 \%(n=192)$ of patients had WtHR higher than 0.5 . As expected, overweight and obese individuals had higher WtHR than normal-weight subjects $(0.49 \pm 0.04$ and $0.55 \pm 0.06$ vs. $0.44 \pm 0.15$, respectively, $p<0.001)$. However, no significant differences in the waist-hip ratio were found comparing different-weight-status participants.

3.2. Glycemic and Metabolic Control. Study subjects' mean $\mathrm{HbAlc}$ was $8.5 \pm 2 \%(69.2 \pm 2 \mathrm{mmol} / \mathrm{mol}) .32 .7 \%(n=289)$ of patients had optimal glycemic control. The best glycemic control was recorded in the group of youngest patients: patients aged 1-4yrs and 5-9yrs had significantly lower HbAlc compared to patients aged 10-14 yrs, 15-19yrs, and $\geq 20$ yrs $(7.3 \pm 1 \%$ and $7.5 \pm 1.2 \%$ vs. $8.5 \pm 1.9 \%, 8.9 \pm 2.1 \%$, and $8.6 \pm 1.9 \%$, respectively, $p<0.05)$. In all age groups, females had significantly higher $\mathrm{HbAlc}$ than males, except in the youngest 1-4 yrs of age group (Table 2).

The average insulin dose was $0.83 \pm 0.3 \mathrm{U} / \mathrm{kg} / \mathrm{d}$ for the whole cohort. Adjusted for diabetes duration, patients with optimal glycemic control had a lower insulin dose compared to patients with suboptimal HbA1c $(0.76 \pm 0.31 \mathrm{U} / \mathrm{kg} / \mathrm{d}$ vs. $0.87 \pm 0.29 \mathrm{U} / \mathrm{kg} / \mathrm{d}$, respectively, $p<0.001)$. In the whole cohort, $30.2 \%$ of patients were on insulin pumps. HbAlc of

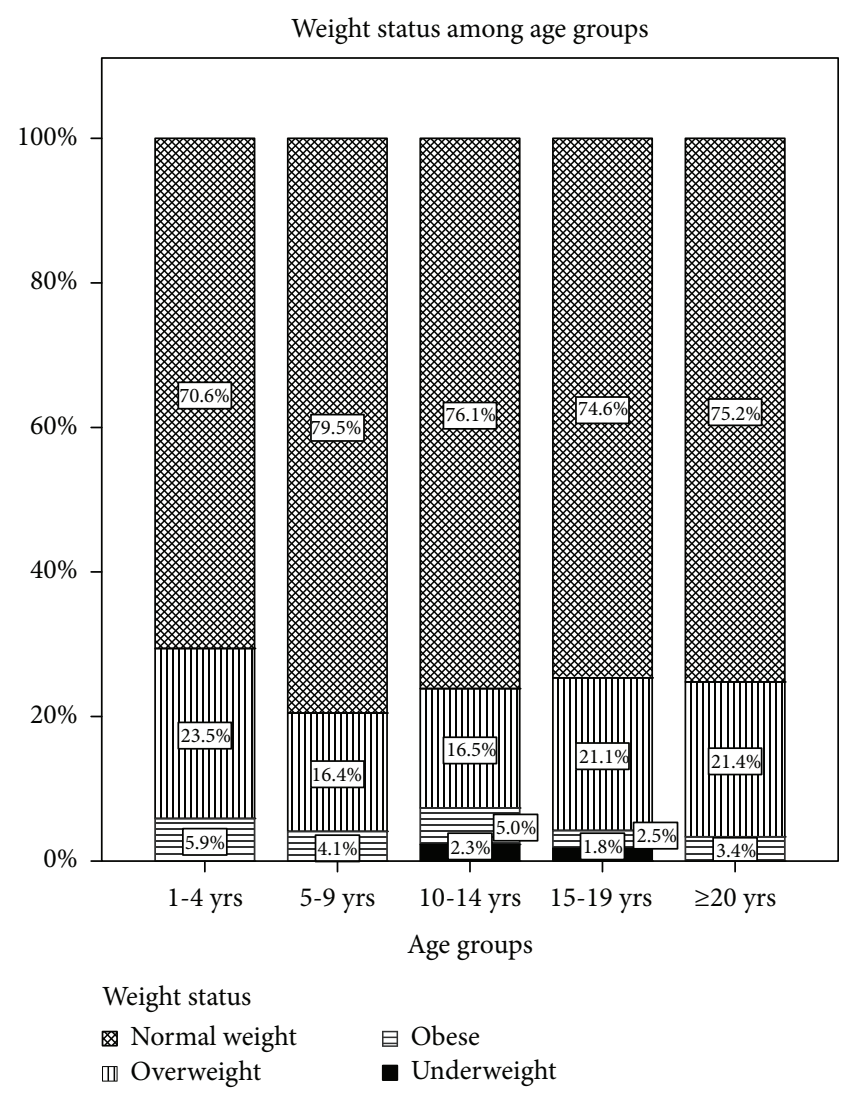

FIGURE 1: Normal weight, overweight, obese, and underweight frequency among different age groups.

patients treated with insulin pumps and multiple daily injections (MDI) was $8.5 \pm 2 \%$ and $8.4 \pm 1.8 \%$, respectively, $p>0.05$; also, there was a similar proportion of subjects with optimal glycemic control in insulin pump users or those on MDI (29.4\% and 30.6\%, respectively, $p>0.05$ ).

Dyslipidemia was found in 62.6\% $(n=552)$ of the total cohort. Increased total cholesterol was found in $28.2 \%$ $(n=249)$ of patients, increased LDL in 54.9\% $(n=484)$, increased Tg in 9.2\% $(n=81)$, and decreased HDL in $13.5 \%$ $(n=119)$ of patients. The frequency of dyslipidemia was similar among all age groups: $50 \%(n=8)$ among patients aged $1-4$ years, $52 \%(n=62)-5-9$ years, $64.7 \%(n=141)-$ 10-14 years, 64.4\% $(n=183)-15-19$ years, and $64.7 \%$ $(n=156)-\geq 20$ years.

Dyslipidemia was more frequent in the group with poor glycemic control compared to that with optimal glycemic control $(66.9 \%$ vs. $53.6 \%$, respectively, $p<0.001)$. Also, the $\mathrm{HbA1c}$ level was significantly higher in patients with dyslipidemia compared to patients with a normal lipid profile $(8.8 \pm 2.1 \%$ vs. $8 \pm 1.7 \%$, respectively, $p<0.001)$. A significantly higher prevalence of dyslipidemia was found in patients with WtHR exceeding 0.5 compared to subjects whose WtHR was less than 0.5 ( $73.4 \%$ vs. $26.6 \%$, respectively, $p<0.001)$.

Significant direct correlations between the levels of $\mathrm{HbAlc}$ and total cholesterol, LDL, and $\mathrm{Tg}$ and reverse correlation between the levels of HbAlc and HDL were found (Figure 2). 
TABLE 1: Clinical characteristics according to weight group.

\begin{tabular}{|c|c|c|c|c|}
\hline & \multicolumn{4}{|c|}{ Weight group } \\
\hline & Normal weight $\%(N)$ & Overweight \% $(N)$ & Obese $\%(N)$ & Underweight $\%(N)$ \\
\hline All & $75.8(666)$ & $19.5(171)$ & $3.6(32)$ & $1.1(10)$ \\
\hline Using insulin pumps & $30.6(204)$ & $30.4(52)$ & $25(8)$ & 0 \\
\hline Optimal glycemic control & $34.5(230)$ & $27.5(47)$ & $21.9(7)$ & $30(3)$ \\
\hline $\mathrm{WtHR} \geq 0.5$ & $11.1(74)$ & $50.9(87)^{*}$ & $84.4(27)^{*}$ & $10(1)$ \\
\hline Dyslipidemia & $61.4(408)$ & $66.7(114)$ & $68.8(22)$ & $60(6)$ \\
\hline Hypertension & $25.6(168)$ & $40.6(69)^{*}$ & $65.6(21)^{*}$ & $50(5)$ \\
\hline \multicolumn{5}{|l|}{ Microvascular complications } \\
\hline Retinopathy & $11(72)$ & $11.7(20)$ & $6.3(2)$ & 0 \\
\hline Neuropathy & $9.6(63)$ & $17(29)^{*}$ & $12.5(4)$ & $10(1)$ \\
\hline Elevated AER & $10.2(66)$ & $8.5(14)$ & $9.4(3)$ & 0 \\
\hline
\end{tabular}

HbAlc: glycosylated hemoglobin; WtHR: waist-to-height ratio; AER: albumin excretion rate. ${ }^{*} p<0.05$, compared to the normal-weight group.

TABLE 2: HbA1c levels between genders in different age groups.

\begin{tabular}{lcc}
\hline $\begin{array}{l}\text { Gender } \\
\text { Age group }\end{array}$ & $\begin{array}{c}\text { Males } \\
\text { Mean HbA1c }(\%)\end{array}$ & $\begin{array}{c}\text { Females } \\
\text { Mean HbA1c (\%) }\end{array}$ \\
\hline 1-4 yrs & $7.3 \pm 1.2$ & $7.2 \pm 0.5$ \\
5-9 yrs & $7.3 \pm 1.1^{*}$ & $7.8 \pm 1.3^{*}$ \\
$10-14$ yrs & $8.2 \pm 1.7^{*}$ & $8.7 \pm 2^{*}$ \\
$15-19$ yrs & $8.6 \pm 2.1^{*}$ & $9.2 \pm 2.2^{*}$ \\
$\geq 20$ yrs & $8.4 \pm 1.9^{*}$ & $8.7 \pm 2^{*}$
\end{tabular}

HbAlc: glycosylated hemoglobin. ${ }^{*} p<0.001$ comparing HbAlc between males and females for the same age group.

A logistic regression was carried out to assess the predictors for the likelihood that the patient would or would not have dyslipidemia. Binary variable "Dyslipidemia" was coded as " 1 " if present and " 0 " if absent. The full model containing continuous predictors, HbA1c levels and WtHR, was statistically significant, $\chi^{2}=39.473, p<0.001$, indicating that the model was able to differentiate between patients with and without dyslipidemia. Analysis of predictors on the probability of dyslipidemia is shown in Table 3.

The logistic regression model could be expressed as

$$
\begin{aligned}
\text { Probability }(\text { Dyslipidemia }) & =\frac{1}{1+e^{-z}}, \\
z & =-3.525+0.207 * X_{1}+5.113 * X_{2},
\end{aligned}
$$

where $e$ is the base of the natural logarithm, $X_{1}$ is HbAlc, and $X_{2}$ is WtHR.

Overall model predictions were successful in $62.1 \%$. Binary logistic regression indicated that $\mathrm{HbAlc}$ and $\mathrm{WtHR}$ are significant predictors of likelihood of dyslipidemia. Cook's distances for the model ranged from a minimum of 0.0058 to a maximum of 0.0907 . The maximum values of DFBETA for $\mathrm{HbAlc}$ and WtHR were 0.003 and 0.2 , respectively.
Impairment of all lipid fractions' metabolism and glycemic control was dependent on diabetes duration. The linear regression models are presented in Figure 3, showing levels of $\mathrm{HbA1c}$, total cholesterol, LDL cholesterol, and Tg directly, and HDL cholesterol concentrations negatively related with duration of diabetes.

In linear regression models, controlled for diabetes duration and glycemic control, BMI $z$-scores were weakly but significantly negatively associated with HDL $(r=-0.095$, $p=0.005)$ and directly related to LDL and Tg concentrations $(r=0.086$ and $p=0.011$ and $r=0.088$ and $p=0.009$, respectively).

3.3. Blood Pressure and Microvascular Complications. Hypertension was diagnosed in $29.8 \%(n=263)$ of patients. It was more frequent among males compared to females $(34.5 \%$ vs. $26.1 \%, p=0.007)$. Hypertension was diagnosed more often in children $(<18$ yrs) than in adults $(18-25$ yrs $)(36.1 \%$ vs. $18 \%$, respectively, $p<0.001)$. Controlled for age and gender, the direct relationship between SBP, DBP, and BMI $z$-scores was found $(r=0.227$ and $p<0.001$ and $r=0.139$ and $p<0.001$, respectively).

In the whole cohort, $212(24 \%)$ subjects were diagnosed with at least one microvascular complication. Retinopathy was diagnosed in $10.8 \%(n=94)$, neuropathy in $11.5 \%(n=97)$, and elevated AER in $9.4 \%(n=83)$ of participants.

Glycemic control, duration of diabetes, and microvascular complications were significantly related. Hypertension was more frequent among patients with elevated AER. Prevalence of dyslipidemia was higher among patients with neuropathy. Comparison of patients according to the presence of diabetes complications is shown in Table 4.

Patients with an altered lipid profile had higher frequency of at least one microvascular complication compared to patients with normal levels of lipids (27.2 vs. $18.8 \%$, respectively, $p=0.005$ ); the same trend was found in patients with hypertension vs. patients with normal BP (25.9 vs. $23.2 \%$, respectively, $p<0.001)$. 


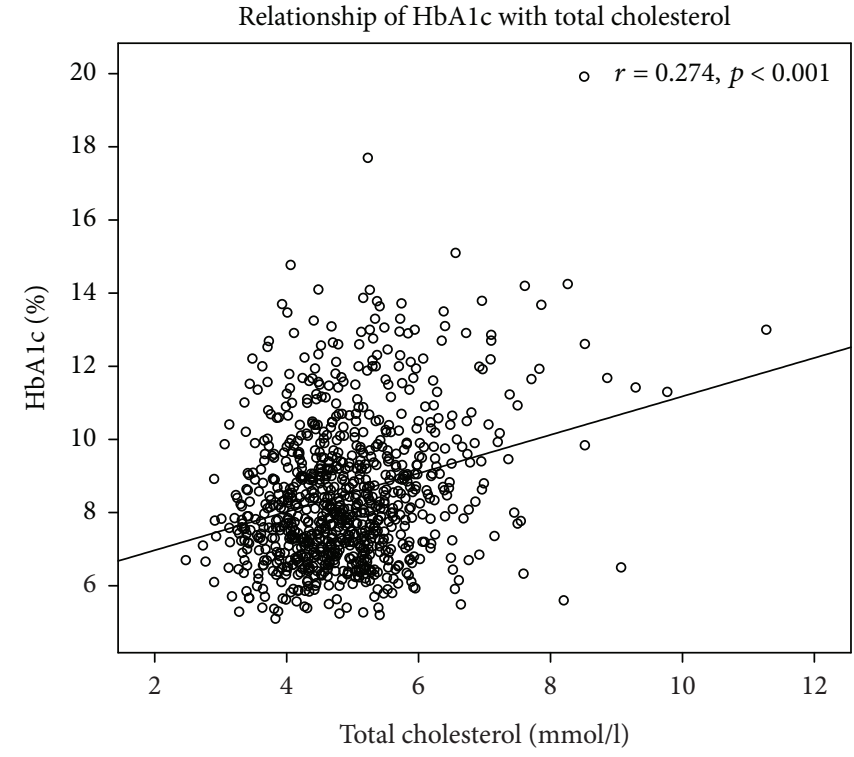

(a)

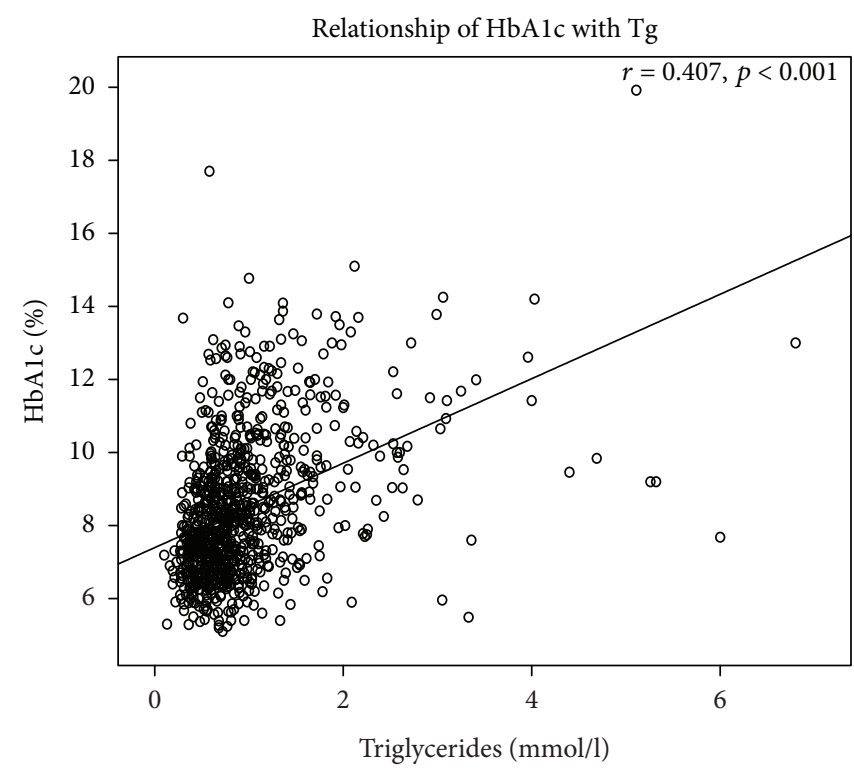

(c)

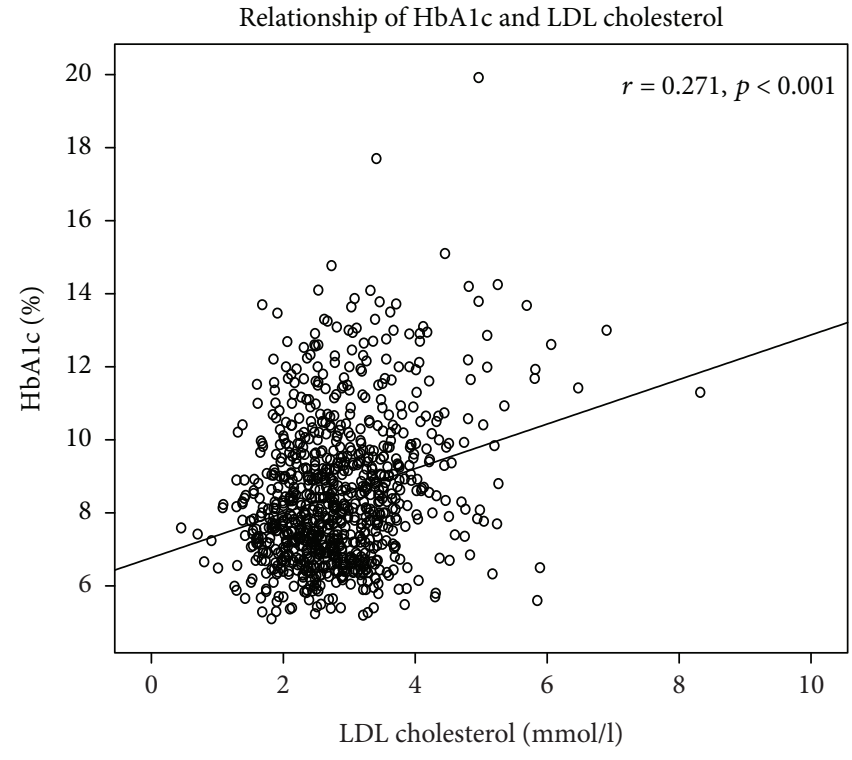

(b)

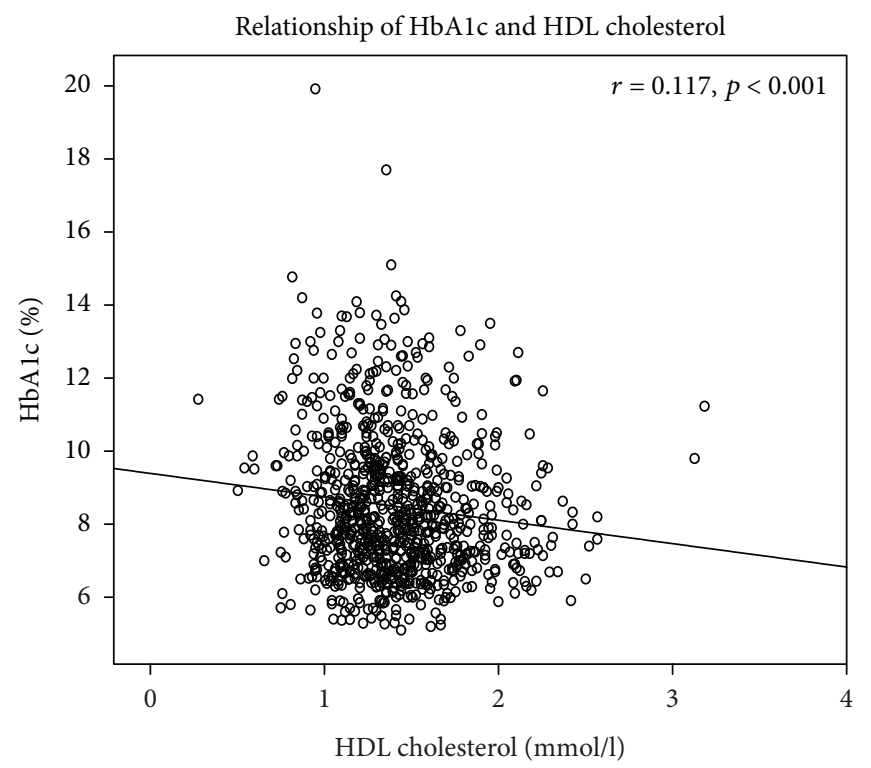

(d)

Figure 2: Correlations between levels of glycosylated hemoglobin (HbA1c) and lipids: (a) relationship of HbA1c and total cholesterol, (b) relationship of HbAlc and low density-lipoprotein cholesterol (LDL), (c) relationship of HbAlc and triglycerides (Tg), and (d) relationship of $\mathrm{HbAlc}$ and high density-lipoprotein cholesterol (HDL).

TABLE 3: Logistic regression: analysis of predictors on "Dyslipidemia”.

\begin{tabular}{lcccccc}
\hline Predictor & $\beta$ & SE $\beta$ & Wald's $\chi^{2}$ & $p$ & OR & Lower \\
\hline Constant & -3.525 & 0.813 & 18.793 & $<0.001$ & 0.029 & NA \\
HbAlc & 0.207 & 0.042 & 24.632 & $<0.001$ & 1.229 & 1.133 \\
WtHR & 5.113 & 1.674 & 9.327 & 0.002 & 166.153 & 6.244 \\
\hline
\end{tabular}

HbAlc: glycosylated hemoglobin; WtHR: waist-to-height ratio; $\beta$ : coefficients estimated from the data; SE: standard error; OR: odds ratio; CI: confidence interval; NA: not available. Cox and Snell $R^{2}=0.046$; Nagelkerke $R^{2}=0.063$. 


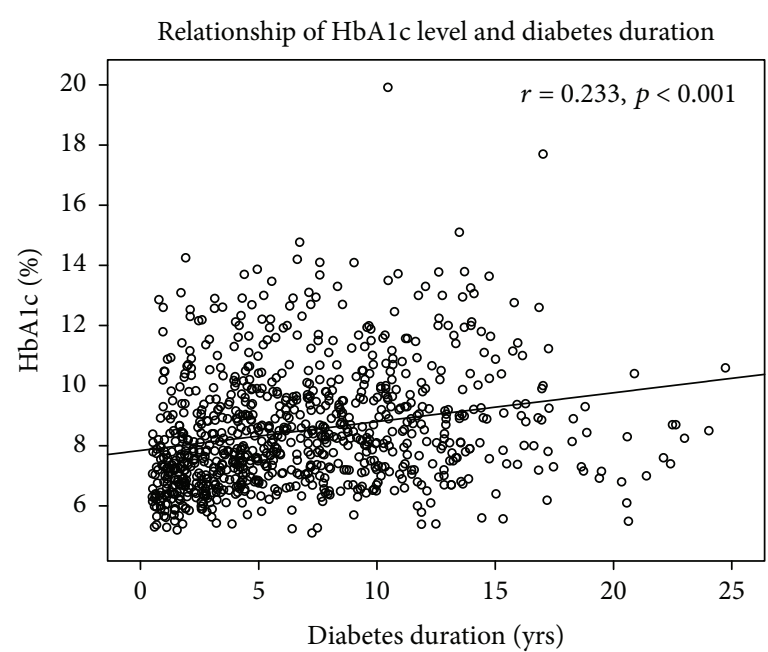

(a)

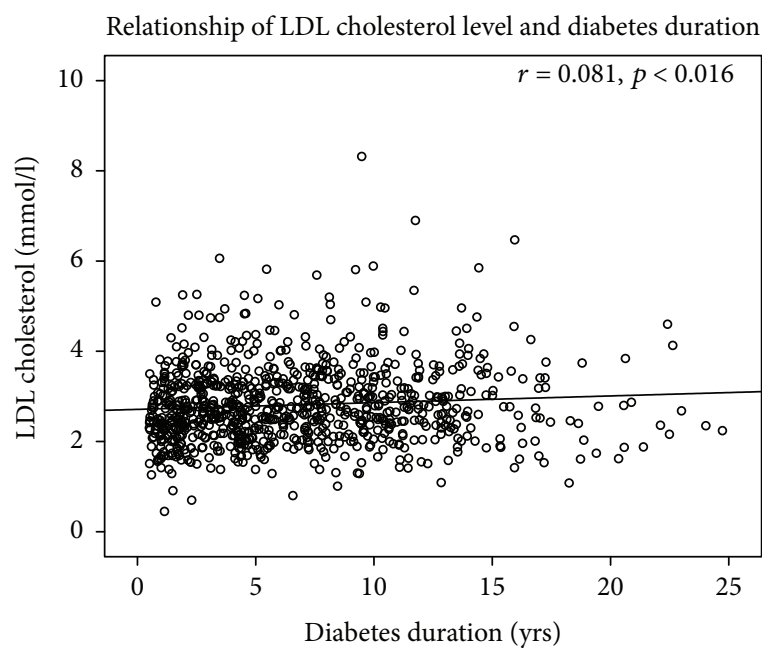

(c)

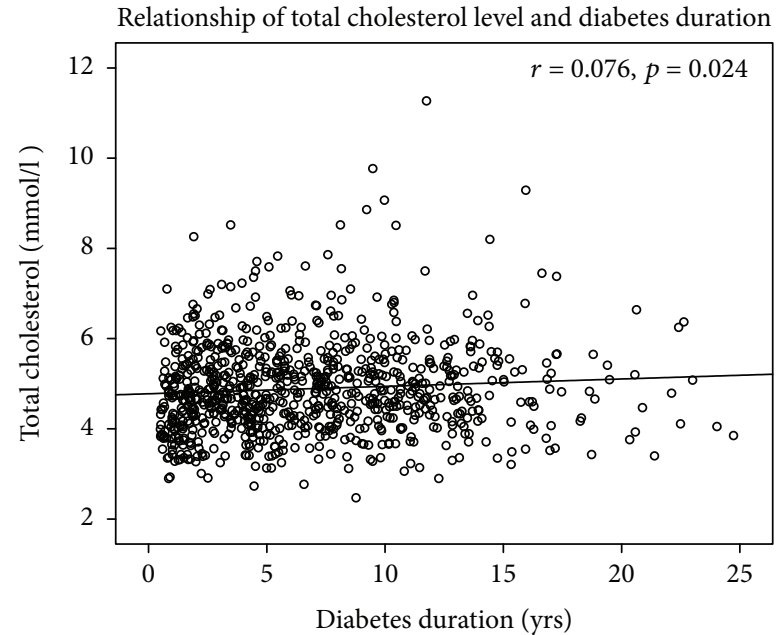

(b)

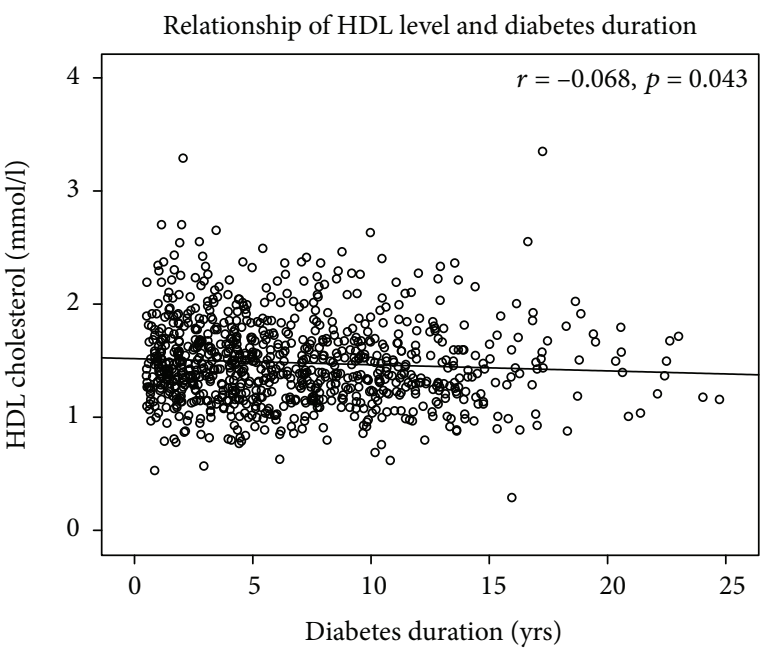

(d)

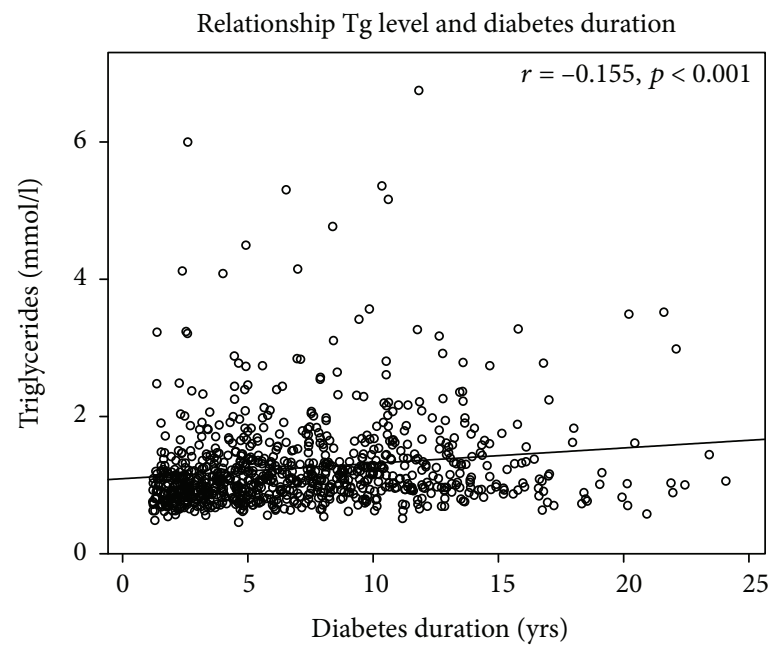

(e)

FIGURE 3: Correlations between diabetes and metabolic control parameters: (a) relationship of diabetes duration and glycosylated hemoglobin (HbAlc), (b) relationship of diabetes duration and total cholesterol, (c) relationship of diabetes duration and low density-lipoprotein cholesterol (LDL), (d) relationship of diabetes duration and high density-lipoprotein cholesterol (HDL), and (e) relationship of diabetes duration and triglycerides (Tg). 
TABLE 4: Clinical characteristics according to presence of diabetic microvascular complications.

\begin{tabular}{|c|c|c|c|c|c|c|}
\hline & \multicolumn{2}{|c|}{ Retinopathy } & \multicolumn{2}{|c|}{ Neuropathy } & \multicolumn{2}{|c|}{ AER } \\
\hline & Absent & Present & Absent & Present & Normal & Elevated \\
\hline \multirow{2}{*}{ Duration of DM (yrs) } & $6 \pm 4.2$ & $12.8 \pm 4.4$ & $6.2 \pm 4.5$ & $11 \pm 4.7$ & $6.4 \pm 4.6$ & $9.3 \pm 5.7$ \\
\hline & \multicolumn{2}{|c|}{$p<0.001$} & \multicolumn{2}{|c|}{$p<0.001$} & \multicolumn{2}{|c|}{$p<0.001$} \\
\hline \multirow{2}{*}{ HbAlc (\%) } & $8.3 \pm 1.8$ & $10 \pm 2.3$ & $8.4 \pm 1.9$ & $9.3 \pm 2.3$ & $8.4 \pm 1.9$ & $9.5 \pm 2.4$ \\
\hline & \multicolumn{2}{|c|}{$p<0.001$} & \multicolumn{2}{|c|}{$p<0.001$} & \multicolumn{2}{|c|}{$p<0.001$} \\
\hline \multirow{2}{*}{$\%$ of participants with dyslipidemia } & 61.9 & 70.2 & 61.4 & 74.2 & 62.1 & 69.9 \\
\hline & \multicolumn{2}{|c|}{$p=0.117$} & \multicolumn{2}{|c|}{$p=0.014$} & \multicolumn{2}{|c|}{$p=0.164$} \\
\hline \multirow{2}{*}{$\%$ of participants with hypertension } & 31.2 & 23.7 & 30.4 & 30.2 & 29.2 & 41.5 \\
\hline & \multicolumn{2}{|c|}{$p=0.083$} & \multicolumn{2}{|c|}{$p=0.9$} & \multicolumn{2}{|c|}{$p=0.031$} \\
\hline
\end{tabular}

DM: diabetes mellitus; HbA1c: glycosylated hemoglobin; AER: albumin excretion rate.

\section{Discussion}

Here, we present population-based study results for metabolic control, obesity, and hypertension in young people under the age of 25 with T1D treated by intensive insulin therapy, whose diabetes duration was more than 6 months.

The principal finding of our study is an unusually high frequency of dyslipidemia among pediatric and young adult patients with T1D compared to previously published data from other studies reporting dyslipidemia in $3.8 \%$ to $30.3 \%$ of subjects with T1D $[7,20]$. These striking differences in the prevalence of dyslipidemia might partly be explained by different cutoff levels of lipids used in different studies. In some reports, $\mathrm{ADA}$ and National Cholesterol Education Program recommendations were used, defining dyslipidemia as TGlevel $>1.7 \mathrm{mmol} / \mathrm{l}$, LDL cholesterol level $>3.36 \mathrm{mmol} / \mathrm{l}$, HDL cholesterol level $<1.03 \mathrm{mmol} / \mathrm{l}$, or total cholesterol $>$ $5.17 \mathrm{mmol} / \mathrm{l}$ [20]. In other studies, dyslipidemia was defined as physician-diagnosed and recorded in medical documentation [7]. In our study, we used the ISPAD guidelines for the definition of optimal lipid levels [14]. Therefore, the use of different guidelines and normative data is certainly affecting the reported frequency of dyslipidemia in patients with T1D, and the comparisons between such studies are limited.

Interestingly, dyslipidemia in our study was present with similar frequency in all age groups and was directly related to diabetes duration and worse glycemic control that were independent factors influencing the occurrence of dyslipidemia in our cohort. Only after adjustment for diabetes duration and glycemic control was lipid fraction concentrations found to have a weak association with adiposity expressed in BMI $z$-scores. However, in our study, we reported slightly lower frequency of weight problems among young type 1 diabetics compared to that in recent studies from USA and Europe [7, 21]. Therefore, the overweight and obesity could not explain high rates of dyslipidemia in our cohort. On the contrary, the frequency of overweight youth among T1D patients seems to increase over time, as in the present study it was found to be higher (19.5\%) than what was reported in 2013 in patients with T1D in Lithuania (13.4\%) [22]. Furthermore, overweight and obese patients in our study had worse glycemic control and higher frequency of hypertension compared to normal-weight subjects, which is compatible with the results reported in other studies highlighting obesity among diabetic patients becoming a considerable health problem, affecting both adults and children $[7,21]$.

We found a significantly higher waist-to-height ratio in overweight and obese groups and in those with at least one lipid fraction out of the normal values. The waist-to-height ratio appeared to be a more sensitive parameter in defining risk of obesity and dyslipidemia than the waist-hip ratio, traditionally used in an adult population in the definition of central obesity. Several studies showed that the waist-toheight ratio is a better indicator than BMI and the waisthip ratio for evaluating obesity and predicting risks for diabetes, hypertension, and CVD [11,23]. The cutoff of 0.5 for the waist-to-height ratio was proved to be optimal in detecting abdominal obesity, metabolic syndrome, and the associated health risks [23].

We reported the mean $\mathrm{HbAlc}$ of $8.5 \pm 2 \%$ in the whole cohort, which is markedly higher than the recommended optimal glycemic control. We found that young females have worse glycemic control than males, which is consistent with other studies' results [7,24]. Of all age groups, patients aged 15-19 yrs have the worst glycemic control, probably because of adjustments in the endocrine system, and increased independence in diabetes care during adolescence makes achieving optimal HbAlc really difficult [25]. We observed that dyslipidemia was directly related to HbAlc levels. A positive correlation was found between the level of $\mathrm{HbAlc}$ and that of total cholesterol, LDL cholesterol, and Tg. These findings are in agreement with data from previous studies and provide further evidence that good glycemic control in young age would have a positive impact on lipid metabolism $[26,27]$.

Our analysis showed that levels of HbAlc and all lipid fraction concentrations were significantly related to the duration of diabetes. The link between T1D duration and microvascular complications and other CVD risk factors has been discussed by other authors [20,28]. Previously published data from a study in Lithuanian T1D patients showed positive associations between the duration of diabetes and 
levels of total cholesterol, LDL cholesterol, and triglycerides [22]. Diabetic nephropathy was reported as the most common diabetic complication, with longer diabetes duration having a significant impact for the development of microalbuminuria [20].

Dyslipidemia in T1D has been shown to be associated with the early development of cardiac and vascular abnormalities [6]. Cholesterol is well known to be one of the key players in the process of atherosclerosis [29]. Epidemiological studies in diabetic patients have shown that increased LDL and decreased HDL cholesterol levels are associated with an increased cardiovascular risk [30]. In accordance with other studies, increased LDL cholesterol levels were the most prevalent and hypertriglyceridemia the least prevalent lipid abnormality in our cohort of young patients with T1D [31]. High levels of triglycerides were shown to be accompanied by a high rate of microangiopathic alterations [31]. Since poor glycemic control can result in increased levels of triglycerides and LDL and decreased HDL cholesterol levels, optimization of glycemic control is essential in controlling lipid levels [30].

Physical activity, smoking, alcohol consumption, and dietary habits were not included in our analysis, constituting one of the limitations of this study; however, studies show the importance of these factors for CVD risk in T1D [6]. Smoking was reported to be a significant player in the progression of atherosclerotic changes of arteries in the Pittsburgh Epidemiology of Diabetes Complications Study [32]. It is known that physical activity positively affects $\mathrm{BP}$, lipid profile, and weight; therefore, it is necessary to decrease physical inactivity in T1D patients $[6,32]$.

Even though ADA and AHA have clinical recommendations for preventing dyslipidemia in youth with diabetes, there is still lack of clinical trial data on treatment efficacy and safety of dyslipidemia in these patients [33]. Recent data reviews suggest that dyslipidemia is one of the potentially modifiable CVD risk factors; therefore, there is a need for clinical trials to examine the safety and efficacy of lipid-lowering drugs and their impact on future health outcomes [33, 34].

In our cohort, we found a higher incidence of hypertension (29.8\%), especially in children, compared to other authors [7, 23]. This high frequency of hypertensive patients might possibly be explained by unrecognized "white-coat" hypertension, whose prevalence in population-based studies was found to be up to $29.2 \%$, and it is suggested that white-coat hypertension could be present in about onethird of subjects with high blood pressure [35]. This type of hypertension may be identified using BP monitoring at home, elucidating the frequency of real hypertension.

We found a significant correlation between SBP, DBP, and BMI $z$-scores. Our results support findings from other studies that weight management is one of the principal strategies to lower the risk of CVD in T1D patients. In the future, it is expected that metformin would also bring some benefits for obese youth with T1D [36, 37].

We report here similar frequency of microvascular complications among young T1D patients, compared to recently published data [20]. Higher frequency of hypertension was found in patients with elevated AER. Hypertension is one of the key risk factors for the development of nephropathy, and management of BP is essential in reducing the risk of kidney damage [20].

We discussed several limitations of our study. We did not perform BP monitoring at home, which would have elucidated the real prevalence of hypertensive and prehypertensive patients. Furthermore, in our cohort, we did not assess apolipoprotein B concentrations and carotid artery intimamedia thickness, which are both significant predictors of CVD risk [38].

Finally, the findings of our study highlight that the management of T1D should be multifaceted and most importantly include glycemic control, weight management, and dyslipidemia treatment.

\section{Data Availability}

The data used to support the findings of this study are available from the corresponding author upon request.

\section{Disclosure}

The abstract "Prevalence of Cardiovascular Risk Factors and Obesity in Youth with Type 1 Diabetes in Lithuania" was presented at the $55^{\text {th }}$ Annual ESPE conference on 10-12 Sep 2016 (Nr. 86 P-P2-277). The research project "Genetic Diabetes in Lithuania" was carried out during 2012-2016. The article "The Course of Diabetes in Children, Adolescents and Young Adults: does the Autoimmunity Status Matter" by Verkauskiene et al. (BMC Endocrine Disorders (2016)16:61) described the whole cohort of the project and focused on $\beta$-cell autoimmunity and diabetes course according to the presence of pancreas antibodies. In this article, we also compared data with the data from "The Risk of Early Cardiovascular Disease in Lithuanian Diabetic Children and Adolescents: a Type 1 Diabetes Register Database Based Study" by Dobrovolskiene et al. (Diabetes Res Clin Pract. 2013;100(1):119-25), which analyzed cardiovascular risk in youth with T1D in Lithuania and was conducted at the same research center.

\section{Conflicts of Interest}

The authors declare that there is no conflict of interest regarding the publication of this article.

\section{Acknowledgments}

The research project "Genetic Diabetes in Lithuania" was supported by a grant from the Research Council of Lithuania Lithuanian-Swiss program "Research and Development" (CH-3-ŠMM-01/09) and the Federal Department of Foreign Affairs of Switzerland.

\section{References}

[1] World Health Organization, Leading causes of death in Europe, WHO Regional Office for Europe, Copenhagen, 2012. 
[2] Z. Milicevic, I. Raz, S. D. Beattie et al., "Natural History of Cardiovascular Disease in Patients With Diabetes: Role of hyperglycemia," Diabetes Care, vol. 31, Supplement 2, pp. S155-S160, 2008.

[3] E. Selvin, J. Coresh, S. H. Golden et al., "Glycemic Control, Atherosclerosis, and Risk Factors for Cardiovascular Disease in Individuals With Diabetes: The Atherosclerosis Risk in Communities study," Diabetes Care, vol. 28, no. 8, pp. 19651973, 2005.

[4] S. S. Soedamah-Muthu, J. H. Fuller, H. E. Mulnier, V. S. Raleigh, R. A. Lawrenson, and H. M. Colhoun, "High Risk of Cardiovascular Disease in Patients With Type 1 Diabetes in the U.K.: A cohort study using the General Practice Research Database," Diabetes Care, vol. 29, no. 4, pp. 798-804, 2006.

[5] R. F. Hamman, R. A. Bell, D. Dabelea et al., "The SEARCH for diabetes in youth study: rationale, findings, and future directions," Diabetes Care, vol. 37, no. 12, pp. 3336-3344, 2014.

[6] J. K. Snell-Bergeon and K. Nadeau, "Cardiovascular disease risk in young people with type 1 diabetes," Journal of Cardiovascular Translational Research, vol. 5, no. 4, pp. 446-462, 2012.

[7] M. J. Redondo, N. C. Foster, I. M. Libman et al., "Prevalence of cardiovascular risk factors in youth with type 1 diabetes and elevated body mass index," Acta Diabetologica, vol. 53, no. 2, pp. 271-277, 2016.

[8] R. Verkauskiene, E. Danyte, R. Dobrovolskiene et al., "The course of diabetes in children, adolescents and young adults: does the autoimmunity status matter?," BMC Endocrine Disorders, vol. 16, no. 1, p. 61, 2016.

[9] J. J. Couper, M. J. Haller, A. G. Ziegler, M. Knip, J. Ludvigsson, and M. E. Craig, "Phases of type 1 diabetes in children and adolescents," Pediatric Diabetes, vol. 15, Supplement 20, pp. 18-25, 2014.

[10] World Health Organization (WHO), Waist circumference and waist-hip ratio: report of a WHO expert consultation, World Health Organization, Geneva, 2008.

[11] M. Ashwell and S. D. Hsieh, "Six reasons why the waist-toheight ratio is a rapid and effective global indicator for health risks of obesity and how its use could simplify the international public health message on obesity," International Journal of Food Sciences and Nutrition, vol. 56, no. 5, pp. 303-307, 2005.

[12] National High Blood Pressure Education Program Working Group on High Blood Pressure in Children and Adolescents, "The fourth report on the diagnosis, evaluation, and treatment of high blood pressure in children and adolescents," Pediatrics, vol. 114, no. 2, pp. 555-576, 2004.

[13] P. K. Whelton, R. M. Carey, W. S. Aronow et al., "2017 ACC/ AHA/AAPA/ABC/ACPM/AGS/AphA/ASH/ASPC/NMA/PCNA guideline for the prevention, detection, evaluation, and management of high blood pressure in adults: executive summary: a report of the American College of cardiology/ American Heart Association Task Force on Clinical Practice Guidelines," Circulation, vol. 138, no. 17, pp. e426-e483, 2018.

[14] K. C. Donaghue, R. P. Wadwa, L. A. Dimeglio et al., "Microvascular and macrovascular complications in children and adolescents," Pediatric Diabetes, vol. 15, Supplement 20, pp. 257-269, 2014.

[15] American Diabetes Association, "Standards of medical care in diabetes - 2017," Diabetes Care, vol. 40, Supplement 1, pp. S48-S56, 2017.
[16] T. J. Orchard, K. Y. Forrest, L. H. Kuller, D. J. Becker, and Pittsburgh Epidemiology of Diabetes Complications Study, "Lipid and blood pressure treatment goals for type 1 diabetes: 10-year incidence data from the Pittsburgh Epidemiology of Diabetes Complications Study," Diabetes Care, vol. 24, no. 6, pp. 1053-1059, 2001.

[17] A. J. M. Boulton, D. G. Armstrong, S. F. Albert et al., "Reprint-Comprehensive foot examination and risk assessment: A report of the Task Force of the Foot Care Interest Group of the American Diabetes Association, with endorsement by the American Association of Clinical Endocrinologists," Physical Therapy, vol. 88, no. 11, pp. 1436-1443, 2008.

[18] W. H. Herman, R. Pop-Busui, B. H. Braffett et al., "Use of the Michigan Neuropathy Screening Instrument as a measure of distal symmetrical peripheral neuropathy in type 1 diabetes: results from the Diabetes Control and Complications Trial/ Epidemiology of Diabetes Interventions and Complications," Diabetic Medicine, vol. 29, no. 7, pp. 937-944, 2012.

[19] C. E. Mogensen, K. W. Hansen, S. Nielsen, M. M. Pedersen, M. Rehling, and A. Schmitz, "Monitoring diabetic nephropathy: glomerular filtration rate and abnormal albuminuria in diabetic renal disease-reproducibility, progression, and efficacy of antihypertensive intervention," American Journal of Kidney Diseases, vol. 22, no. 1, pp. 174-187, 1993.

[20] D. Fatma, T. Derya, K. Özlem, and E. İhsan, "Microvascular complications in adolescents with type 1 diabetes mellitus," Journal of Clinical Research in Pediatric Endocrinology, vol. 5, no. 3, pp. 145-149, 2013.

[21] M. van Vliet, J. C. van der Heyden, M. Diamant et al., "Overweight is highly prevalent in children with type 1 diabetes and associates with cardiometabolic risk," The Journal of Pediatrics, vol. 156, no. 6, pp. 923-929, 2010.

[22] R. Dobrovolskienė, G. Mockevičienè, B. Urbonaite, N. Jurgevičienè, R. T. Preikša, and R. Ostrauskas, "The risk of early cardiovascular disease in Lithuanian diabetic children and adolescents: a type 1 diabetes register database based study," Diabetes Research and Clinical Practice, vol. 100, no. 1, pp. 119-125, 2013.

[23] M. Ashwell, P. Gunn, and S. Gibson, "Waist-to-height ratio is a better screening tool than waist circumference and BMI for adult cardiometabolic risk factors: systematic review and meta-analysis," Obesity Reviews, vol. 13, no. 3, pp. 275-286, 2012.

[24] K. O. Schwab, J. Doerfer, W. Marg, E. Schober, R. W. Holl, and on behalf of the DPV Science Initiative and the Competence Network Diabetes mellitus, "Characterization of 33488 children and adolescents with type 1 diabetes based on the gender-specific increase of cardiovascular risk factors," Pediatric Diabetes, vol. 11, no. 5, pp. 357-363, 2010.

[25] M. J. Rewers, K. Pillay, C. de Beaufort et al., "Assessment and monitoring of glycemic control in children and adolescents with diabetes," Pediatric Diabetes, vol. 15, Supplement 20, pp. 102-114, 2014.

[26] P. Gunczler, R. Lanes, A. Soros et al., "Coronary artery calcification, serum lipids, lipoproteins, and peripheral inflammatory markers in adolescents and young adults with type 1 diabetes," The Journal of Pediatrics, vol. 149, no. 3, pp. 320 323, 2006.

[27] D. M. Maahs, A. K. Maniatis, K. Nadeau, R. P. Wadwa, K. McFann, and G. J. Klingensmith, "Total cholesterol and high-density lipoprotein levels in pediatric subjects with type 
1 diabetes mellitus," The Journal of Pediatrics, vol. 147, no. 4, pp. 544-546, 2005.

[28] E. E. Fröhlich-Reiterer and M. H. Borkenstein, "Microvascular and macrovascular complications in children and adolescents with type 1 diabetes mellitus," Wiener Medizinische Wochenschrift, vol. 160, no. 15-16, pp. 414-418, 2010.

[29] H. D. Margeirsdottir, J. R. Larsen, C. Brunborg, N. C. Øverby, K. Dahl-Jørgensen, and the Norwegian Study Group for Childhood Diabetes, "High prevalence of cardiovascular risk factors in children and adolescents with type 1 diabetes: a populationbased study," Diabetologia, vol. 51, no. 4, pp. 554-561, 2008.

[30] K. R. Feingold and C. Grunfeld, Diabetes and dyslipidemia, Endotext, South Dartmouth (MA), 2018.

[31] J. J. Chillarón, J. A. Flores Le-Roux, D. Benaiges, and J. PedroBotet, "Type 1 diabetes, metabolic syndrome and cardiovascular risk," Metabolism, vol. 63, no. 2, pp. 181-187, 2014.

[32] R. G. Miller, A. M. Secrest, D. Ellis, D. J. Becker, and T. J. Orchard, "Changing impact of modifiable risk factors on the incidence of major outcomes of type 1 diabetes: the Pittsburgh epidemiology of diabetes complications study," Diabetes Care, vol. 36, no. 12, pp. 3999-4006, 2013.

[33] D. M. Maahs, R. P. Wadwa, K. McFann et al., "Longitudinal lipid screening and use of lipid-lowering medications in pediatric type 1 diabetes," The Journal of Pediatrics, vol. 150, no. 2, pp. 146-150.e2, 2007.

[34] D. M. Maahs, R. P. Wadwa, F. Bishop, S. R. Daniels, M. Rewers, and G. J. Klingensmith, "Dyslipidemia in youth with diabetes: to treat or not to treat?," The Journal of Pediatrics, vol. 153, no. 4, pp. 458-465.e4, 2008.

[35] M. Gorostidi, E. Vinyoles, J. R. Banegas, and A. de la Sierra, "Prevalence of white-coat and masked hypertension in national and international registries," Hypertension Research, vol. 38, no. 1, pp. 1-7, 2015.

[36] J. Anderson, A. S. Peña, T. Sullivan et al., "Does metformin improve vascular health in children with type 1 diabetes? Protocol for a one year, double blind, randomised, placebo controlled trial," BMC Pediatrics, vol. 13, no. 1, p. 108, 2013.

[37] C. Liu, D. Wu, X. Zheng, P. Li, and L. Li, "Efficacy and safety of metformin for patients with type 1 diabetes mellitus: a metaanalysis," Diabetes Technology \& Therapeutics, vol. 17, no. 2, pp. 142-148, 2015.

[38] H. D. Margeirsdottir, K. H. Stensaeth, J. R. Larsen, C. Brunborg, and K. Dahl-Jørgensen, "Early signs of atherosclerosis in diabetic children on intensive insulin treatment: a population-based study," Diabetes Care, vol. 33, no. 9, pp. 2043-2048, 2010. 


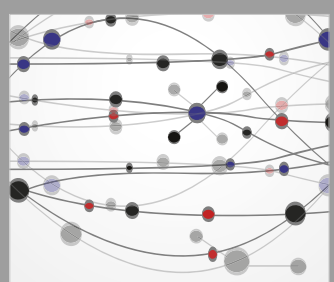

The Scientific World Journal
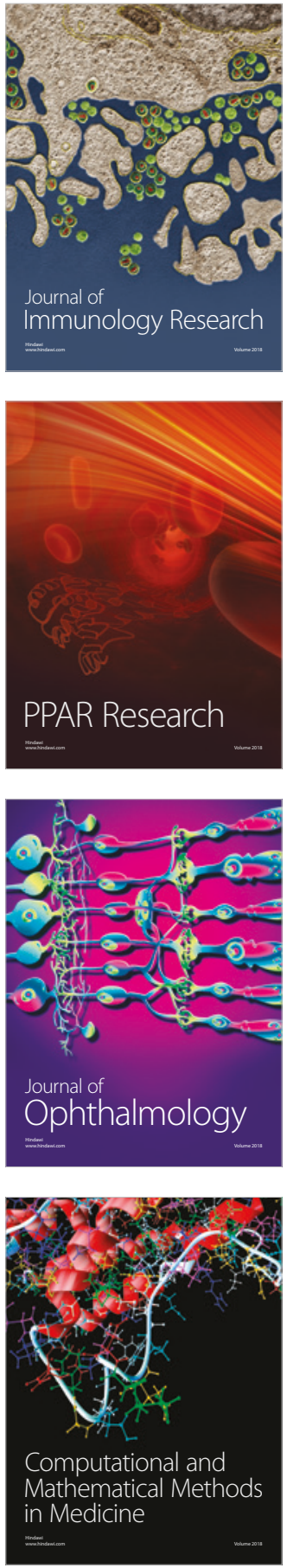

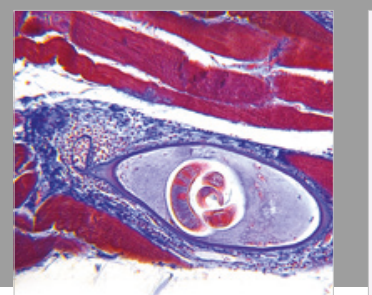

Gastroenterology Research and Practice

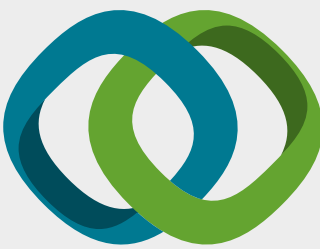

\section{Hindawi}

Submit your manuscripts at

www.hindawi.com
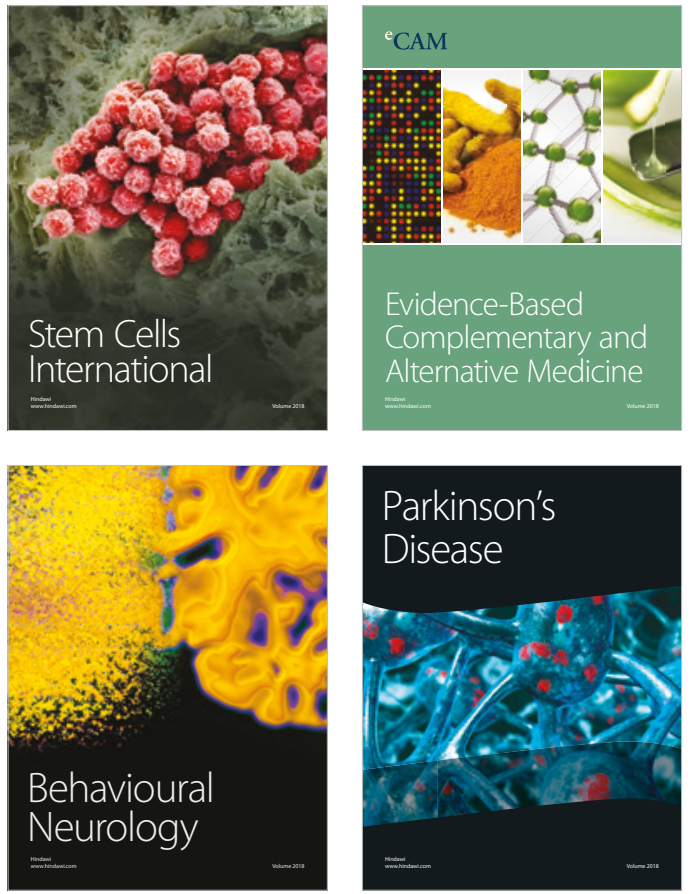

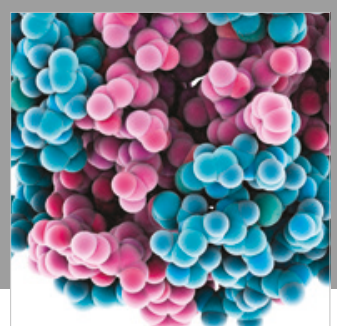

ournal of

Diabetes Research

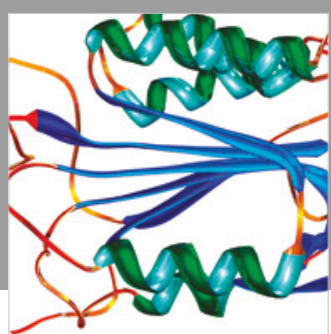

Disease Markers
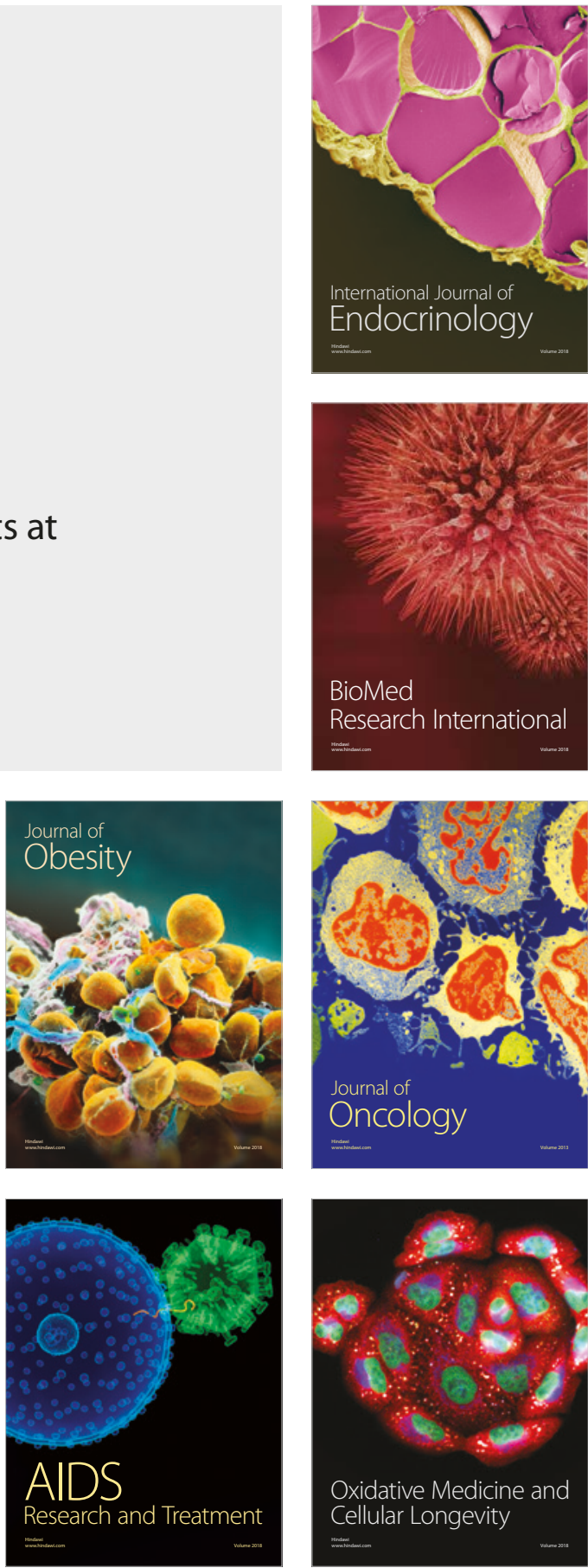